\title{
Correction: Genome-wide DNA methylation analysis of peripheral blood cells derived from patients with first-episode schizophrenia in the Chinese Han population
}

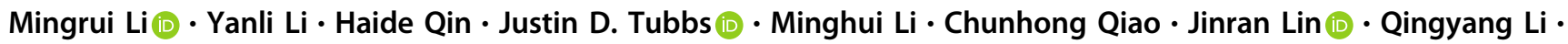
Fengmei Fan $(\mathbb{D} \cdot$ Mengzhuang Gou $(\mathbb{D} \cdot$ Junchao Huang $\cdot$ Jinghui Tong $\cdot$ Fude Yang $\cdot$ Yunlong Tan $\cdot$ Yin Yao $\mathbb{D}$

Published online: 4 January 2021

(C) The Author(s), under exclusive licence to Springer Nature Limited 2021

Correction to: Molecular Psychiatry

https://doi.org/10.1038/s41380-020-00968-0

The authors would like to add following information.

(1) Dr Yin Yao is affiliated with Department of Biostatistics and Computational Biology, Fudan Univeristy;
And Dr. Yao is also affililated with the Human Phenome Institute, Fudan University.

(2) We need to clarify that this scientific project was supported by Shanghai Municipal Science and Technology Major Project (Grant number: 201203), China.

The original article has been corrected. 